\title{
Growth hormone and amino acid supply interact synergistically to control insulin-like growth factor-I production and gene expression in cultured ovine hepatocytes
}

\author{
N M Wheelhouse, A K Stubbs, M A Lomax, J C MacRae ${ }^{1}$ and \\ D G Hazlerigg \\ Department of Agriculture, MacRobert Building, University of Aberdeen, 581 King Street, Aberdeen AB24 5 UA, UK \\ ${ }^{1}$ Rowett Research Institute, Bucksburn, Aberdeen AB21 9SB, UK \\ (Requests for offprints should be addressed to D G Hazlerigg; Email: d.hazlerigg@abdn.ac.uk)
}

\begin{abstract}
Many of the anabolic effects of growth hormone $(\mathrm{GH})$ are indirect, occurring through GH-stimulated production of insulin-like growth factor-I (IGF-I) by the liver. As well as being regulated by $\mathrm{GH}$, plasma IGF-I concentrations have been demonstrated to depend upon the level of dietary protein intake, with low protein diets being associated with reduced circulatory IGF-I levels. This inhibitory effect cannot be reversed by GH injection, suggesting that liver sensitivity to $\mathrm{GH}$ becomes impaired.

To investigate the mechanisms through which protein supply affects GH sensitivity, primary cultures of ovine hepatocytes were grown in defined media, containing various proportions $(0 \cdot 2,1 \cdot 0$ and $5 \cdot 0)$ of jugular amino acid concentrations in fed sheep. Production of IGF-I by these cells was measured after 24 and $48 \mathrm{~h}$ in culture by radioimmunoassay. In the first $24-\mathrm{h}$ period basal IGF-I production was the same in all defined media, and $\mathrm{GH}$ caused an approximately 2 -fold increase in IGF-I release in cells grown in $1 \cdot 0 \times$ or $5 \cdot 0 \times$ amino acid media $(P<0 \cdot 01)$. Although GH appeared to increase IGF-I release in this period for cells grown in $0.2 \times$ amino acid media, this effect was not statistically significant. In the period from 24-48 h in defined media, both basal and GH-stimulated IGF-I production was dependent on amino acid availability $(P<0 \cdot 05$ and $P<0 \cdot 001$ respectively). Factorial analysis of variance demonstrated a strong positive interaction $(P<0 \cdot 001)$ between the effects of amino acid availability and $\mathrm{GH}$, such that $\mathrm{GH}$ increased IGF-I production by more than 2-fold in cells grown in $5 \cdot 0 \times$ amino acid media $(P<0 \cdot 01)$ but had no effect on production by cells grown in $1.0 \times$ or $0 \cdot 2 \times$ amino acid media.
\end{abstract}

Measurement of steady state concentrations of exon 1-derived IGF-I mRNAs using an RNase protection assay demonstrated that the observed effects on IGF-I peptide secretion were strongly associated with parallel effects at the RNA level.

Incorporation of ${ }^{35} \mathrm{~S}$-methionine into cellular proteins over a 4-h period starting $20 \mathrm{~h}$ after transfer to defined culture media was not significantly reduced in $1.0 \times$ compared with $5.0 \times$ amino acid media, although rates under both of these conditions were significantly higher than those seen in $0 \cdot 2 \times$ amino acid media $(P<0 \cdot 01)$. The lack of correspondence between the dose-dependent effects of amino acid supply on cellular protein synthesis and those on basal and GH-stimulated IGF-I production, suggests that amino acid supply modulates IGF-I production through selective mechanisms.

Steady state levels of the CCAAT/enhancer-binding protein $\beta(\mathrm{C} / \mathrm{EBP} \beta)$ isoforms, liver-enriched activating protein (LAP) and liver-enriched inhibitory protein (LIP) were determined by Western blotting. When levels of LAP were expressed relative to LIP levels in the same extracts, a significant decrease in the LAP:LIP ratio was observed in response to amino acid limitation $(P<0 \cdot 05)$.

These data strengthen earlier arguments that synergistic interaction between the effects of amino acids and GH on hepatic IGF-I gene expression underlie nutritiondependent changes in circulating IGF-I titres. The association between these effects and altered levels of $\mathrm{C} / \mathrm{EBP} \beta$ isoforms suggests that CCAAT/enhancer mediated control of IGF-I gene expression may be involved in this phenomenon.

Journal of Endocrinology (1999) 163, 353-361

\section{Introduction}

Many of the anabolic effects of growth hormone $(\mathrm{GH})$, including promotion of lean tissue growth, are mediated by the actions of insulin-like growth factor-I (IGF-I) (Gluckman et al. 1987). Although IGF-I gene expression has been observed in many tissues (Daughaday \& Rotwein 1989), the liver is the predominant source of circulating 
IGF-I (Schwander et al. 1983). As well as being regulated by GH (Daughaday \& Rotwein 1989), plasma IGF-I concentrations have been demonstrated to be dependent upon nutritional status (Sohlstrom et al. 1998). Despite increased GH secretion, circulating IGF-I concentrations decline during feed restriction in cattle (Breier et al. 1988) and anorexia nervosa in humans (Counts et al. 1992), suggesting that undernutrition causes a loss of sensitivity to GH (Elsasser et al. 1989). Consistent with this hypothesis, it has been shown that the IGF-I response to an intravenous $\mathrm{GH}$ challenge is increased by high levels of feed in several species (Breier et al. 1988, Wyn et al. 1991, Bates et al. 1993). Experiments to determine the nutritional components responsible for this altered IGF-I responsiveness indicate that in sheep and in rats, the IGF-I plasma response may be modulated by levels of dietary protein, independently of energy status, suggesting that plasma amino acids may act as metabolic signals (MacRae et al. 1991, VandeHaar et al. 1991, Kriel et al. 1992).

Studies in vitro using primary rat hepatocyte cultures, demonstrate that amino acid limitation is associated with reduced cellular concentrations of IGF-I RNA (Harp et al. 1991, Thissen et al. 1994) and peptide release (Harp et al. 1991). This direct effect of amino acids is one of a large number of examples of direct effects of amino acid limitation on hepatic gene expression - both inhibitory and stimulatory (Marten et al. 1994). In addition, studies have reported effects of amino acid supply on hepatic protein synthesis initiation (Kimball et al. 1991). It remains unclear whether there is a direct causal relationship between the effects observed at a secretory level and changes in steady state RNA levels, or total cellular protein synthesis rates.

In the particular case of IGF-I, uncertainty as to the relationship between RNA levels per se and peptide production is increased by studies showing that nutritional history affects the polysomal association of IGF-I mRNAs in rat liver extracts (Foyt et al. 1991), and that in vitro translatability of IGF-I mRNAs depends upon structure of the $5^{\prime}$ untranslated region (5'UTR) (Yang et al. 1995). This may be highly significant, since the organisation of the IGF-I gene offers the potential for generating mature IGF-I transcripts that differ significantly in this region, depending on whether transcription is initiated in exon 1 or 2 of the IGF-I gene, and if exon 1 is used. Furthermore, within class 1 (exon 1-derived) IGF-I transcripts variation is observed in the $5^{\prime} \mathrm{UTR}$, due to diffuse transcription start site usage (Yang et al. 1995). That these differences may be important in the physiological regulation of IGF-I peptide production is suggested by the finding that nutrition and GH have differential effects on levels of class 1/class 2 (exon 2-derived) IGF-I transcripts found in the liver (Pell et al. 1993).

One particularly intriguing aspect of the in vitro studies performed in rat hepatocytes is the observation that GH and amino acid supply interact to control IGF-I RNA concentration in a synergistic fashion (Thissen et al. 1994). This raises the question of whether the apparent loss of GH sensitivity observed under conditions of poor protein nutrition depends on hormone-nutrient interactions at the mRNA level.

The purpose of the present study was to investigate this possibility in more detail. The first objective was to determine whether synergy was also apparent at the level of peptide production in vitro; secondly, the link between the effects of amino acid supply on IGF-I production and those on cellular protein synthetic rates in hepatocytes was considered. Finally, since previous work has implicated liver-enriched CCAAT/enhancer binding proteins (C/ EBP) in the control of IGF-I gene expression (Nolten et al. 1994), the study examined the effect of amino acid supply on steady state levels of alternative isoforms of the transcription factor $\mathrm{C} / \mathrm{EBP} \beta$.

\section{Materials and Methods}

\section{Preparation of sheep hepatocytes}

Ovine hepatocyes were prepared from the median lobe of livers removed immediately after slaughter from sheep killed at a local abattoir using a modification of previously described methodology (Luo et al. 1995). The lobe was perfused through the hepatic vein via a plastic catheter with $700 \mathrm{ml}$ calcium-free Krebs buffer (Krebs et al. 1974) (0.04\% EGTA) whilst other veins were occluded with haemostats. The lobe was then placed on ice for transport back to the laboratory. During transit (about $20 \mathrm{~min}$ ) perfusion was maintained in ice-cold calcium-free Krebs buffer. At the laboratory the liver lobe was rinsed with $500 \mathrm{ml}$ calcium-free Krebs buffer at $37^{\circ} \mathrm{C}$. Collagenase $(0.05 \%)$ and calcium chloride $(0.05 \%)$ were added to the perfusate and perfusion was maintained on a manual recirculation system for a further $20 \mathrm{~min}$ or until the lobe appeared to be digested.

The digested lobe was placed in a beaker containing approximately $200 \mathrm{ml}$ Krebs buffer, the outer capsule was broken and the cells released into suspension. The suspension was poured into a second beaker. The cells were filtered through three layers of muslin and were washed twice in Krebs buffer before final resuspension in Krebs buffer prior to seeding. Viable cell yield was assessed by counting an aliquot of cell suspension mixed with an equal volume of Trypan blue stain, using an improved Nebauer haemocytometer. In all cell preparations at least $90 \%$ of the cells were viable as determined by ability to exclude Trypan blue.

Cells were plated directly onto $60 \mathrm{~mm}$ (for metabolic labelling experiments) or $90 \mathrm{~mm}$ (for IGF-I and urea production) diameter collagen-coated tissue culture plates in 5 or $10 \mathrm{ml}$ recovery media respectively. The cell seeding density was $1 \times 10^{6}$ viable cells $/ \mathrm{ml}$. Recovery media consisted of Eagle's minimal essential medium 
supplemented with $10 \%$ newborn calf serum, insulin transferrin selenite media supplement (Sigma Chemical Co., Poole, Dorset, UK), 0.4 nM dexamethasone, $0 \cdot 15 \mathrm{nM}$ tri-iodothyronine, antibiotic/antimycotic (Gibco BRL, Paisley, Strathclyde, UK), 4.2 mM sodium acetate, $0.33 \mathrm{mM}$ sodium butyrate, $2.0 \mathrm{mM}$ sodium propionate and $1.15 \mathrm{mM}$ calcium lactate. The cells were incubated at $37{ }^{\circ} \mathrm{C}$ in $5 \% \mathrm{CO}_{2}$ for $4 \mathrm{~h}$ before the recovery media were replaced by $10 \mathrm{ml}$ of the respective incubation media.

\section{Incubation media}

Test media were made using constituents of the RPMI1640 Select-Amine kit (Gibco BRL cat. 17402-017). Hormone and volatile fatty acid concentrations were as described for recovery media. Free amino acid concentrations were $5 \cdot 0 \times, 1 \cdot 0 \times$, and $0.2 \times$ physiological concentrations based upon in vivo ovine portal venous blood data (Lobley et al. 1995).

\section{Harvesting of culture media for analysis}

During experiments, incubation media were replaced every $24 \mathrm{~h}$, and the collected media were immediately frozen at $-70{ }^{\circ} \mathrm{C}$. Prior to analyses of urea production and of IGF-I secretion $10 \mathrm{ml}$ batches of media were lyophilized and reconstituted in $200 \mu \mathrm{H}_{2} \mathrm{O}$.

\section{Assessment of metabolic viability by urea assay}

The metabolic viability of hepatocyte cultures was assessed in terms of urea production. Samples for urea analysis were diluted 20-fold prior to analysis using a commercially available urea-nitrogen assay kit (Sigma catalogue number 6650) according to the supplier's instructions. Under the culture conditions described, urea production remained linear for at least $48 \mathrm{~h}$ in culture.

\section{IGF-I radioimmunoassay}

IGF-I was assayed using recombinant human IGF-I as a standard (Bachem, Saffron Walden, Essex, UK) and a rabbit antiserum to IGF-I (UB2-495, a gift from the National Hormone and Pituitary Program, NIDDK, Baltimore, MD, USA). Rabbit $\gamma$-globulin was obtained from the Scottish antibody distribution unit (Lanarkshire, UK). IGF-I binding proteins were extracted using a modification of a previously described acid-ethanol extraction procedure (Breier et al. 1991). Briefly, $100 \mu \mathrm{l}$ aliquots of redissolved lyophilizate were mixed with $400 \mu \mathrm{l}$ acid/ ethanol. The mixture was incubated on ice for $30 \mathrm{~min}$ and centrifuged at $17000 \mathrm{~g}$ and $4{ }^{\circ} \mathrm{C}$. Two hundred and fifty microlitres supernatant were mixed with $100 \mu \mathrm{l} 0 \cdot 855 \mathrm{M}$ Trizma base (Sigma Chemical Co.) incubated at $-20^{\circ} \mathrm{C}$ overnight and centrifuged at $17000 \mathrm{~g}$ and $4{ }^{\circ} \mathrm{C}$. The supernatant was removed and/or stored at $-70{ }^{\circ} \mathrm{C}$ until use. To minimize the effects of residual binding proteins the extracts were further diluted 1:4 in assay buffer. Due to possible deleterious effects of high salt concentrations on assay binding and possible cross-reactivity of the antibody with insulin, all standards were prepared in reconstituted blank media. The intra- and interassay coefficients of variation were $6 \cdot 73 \%$ and $12 \cdot 23 \%$ respectively. The detection limit for the assay was $80 \mathrm{pg} / \mathrm{ml}$.

\section{Measurement of IGF-I gene expression}

After incubation as required, media were aspirated, and cells were washed with ice-cold PBS. Total cellular RNA was then extracted according to the method of Chomczynski and Sacchi (1987), and quantified by spectrophotometry at $260 \mathrm{~nm}$. Extracted RNA was stored at $-70{ }^{\circ} \mathrm{C}$ until assay.

Steady state expression of the IGF-I gene was measured by RNase protection assay (RPA), using a riboprobe giving a full length protected fragment size of 405 bases corresponding to bases 4-408 of the ovine type-1 IGF-I cDNA (Genbank M30653), using a slight modification of previously published methods (Pell et al. 1993).

Briefly, a cDNA fragment corresponding to the region referred to above was prepared by reverse transcription PCR, ligated into pGEM-4Z+/- (Promega, Southampton, Hampshire, UK, cat. P2161) and cloned in high competency JM109 cells (Promega) following the manufacturer's protocols. Plasmid DNA was extracted using the Wizard Maxiprep system (Promega), according to the supplier's protocol. The sequence and orientation of the cloned fragment was verified by dye-terminator automated sequencing.

Template DNA for in vitro transcription was prepared by restriction digestion of the recombinant plasmid using BamHI (Promega), according to the supplier's protocols, and gel-filtration purification using a Chromaspin 100 column (Clontech, Basingstoke, Hants, UK). In vitro transcription reactions using T7 RNA-polymerase and including $50 \mu \mathrm{Ci}{ }^{32} \mathrm{P}-\alpha \mathrm{UTP}$ (NEN, Hounslow, UK) were conducted using reagents and protocols supplied by Promega. Labelled transcripts were purified using Chromaspin 30 columns (Clontech) according to the supplier's protocol. Transcription efficiency was assessed by scintillation counting of the column purified probe, and was typically better than $90 \%$.

RNase protection assays were conducted using the Ambion RPA-II kit (AMS Biotechnology Ltd., Witney, Oxon, UK), according to the supplier's protocol. Reactions typically included $10 \mu \mathrm{g}$ sample RNA and approximately 100 pg IGF-I riboprobe. As a control for loading variation, a probe for the gluteraldehyde-phosphate dehydrogenase (GAPDH), generously supplied by Dr P Barrett (Rowett Research Institute, Aberdeen, UK), was generated as described previously (Barrett et al. 1996) and included in the same assay reactions. 
Protected fragments were visualised by electrophoresis in 6\% acrylamide gels as described in Barrett et al. (1996), and autoradiography using Amersham Hyperfilm MP (Amersham Life Science Ltd., Little Chalfont, Bucks, UK). Band quantitation was conducted using a LASER densitometer (Molecular Dynamics, Kemsing, Kent, UK) and Phoretix I-D advanced image analysis software (Phoretix International, Newcastle-upon-Tyne, UK).

\section{Cellular protein synthesis rates}

Cellular protein synthesis rates were measured by metabolic labelling with ${ }^{35} \mathrm{~S}$-methionine, in the same test media used in the studies of IGF-I expression. Incubations were carried out over a 3-h period, midway through the overall 48-h incubation used for monitoring the effects on IGF-I and urea production. For these experiments $5 \times 10^{6}$ cells were seeded into $60 \mathrm{~mm}$ dishes in a total volume of $5 \mathrm{ml}$. To ensure that the media conditions were as defined during the labelling period, media were replaced with fresh, pre-warmed media $1 \mathrm{~h}$ before addition of label. Labelling reactions were initiated by the addition of $3.75 \mu \mathrm{Ci}{ }^{35} \mathrm{~S}$-methionine (NEN cat NEG709-A) in $50 \mu \mathrm{l}$ PBS. Cells were then returned to the incubator for a range of times up to $4 \mathrm{~h}$. Labelling reactions were terminated by aspirating the media, washing the cells briefly in ice-cold PBS, and then lysing in $1 \mathrm{ml}$ boiling $10 \mathrm{mM}$ Tris- $\mathrm{HCl}$ and $1 \%$ sodium lauryl sulphate ( $\mathrm{pH} 7 \cdot 5)$. The lysates were scraped into $1.5 \mathrm{ml}$ tubes, passed 5 times through a 25-gauge needle to shear released DNA, heated for $5 \mathrm{~min}$ at $95^{\circ} \mathrm{C}$, and then stored at $-70{ }^{\circ} \mathrm{C}$ until assay.

Incorporation of methionine into proteins was assessed by trichloroacetic acid (TCA) precipitation of cellular proteins. Aliquots $(500 \mu \mathrm{l})$ of cell extracts were mixed with equal volumes of $20 \%$ TCA (ice cold) and allowed to stand on ice for $1 \mathrm{~h}$ to allow a precipitate to form. Tubes were centrifuged at $10000 \boldsymbol{g}$ in a Jouan MR1822 cooled centrifuge for $5 \mathrm{~min}$. The supernatant was discarded and the pellet was resuspended in a further $1 \mathrm{ml} 10 \%$ TCA, and centrifuged once again. This procedure for washing the pellet was repeated a total of 3 times, after which the pellet was redissolved in $1 \mathrm{ml} 0.6 \mathrm{M} \mathrm{NaOH}$. Aliquots $(500 \mu \mathrm{l})$ of redissolved material were transferred to scintillation vials and mixed with $2.5 \mathrm{ml}$ scintillant (Ultima Gold; Canberra Packard, Pangbourne, Berks, UK), and radioactivity was determined by counting on a Canberra Packard liquid scintillation counter. Molar incorporation rates were calculated based on the specific activity of the ${ }^{35} \mathrm{~S}$-methionine, i.e. taking into account the change in methionine concentration with the changing total amino acid content in the defined media.

\section{Measurement of $C / E B P \beta$ protein isoforms}

The expression of isoforms of $\mathrm{C} / \mathrm{EBP} \beta$ was determined by immunological staining of Western blots of whole-cell extracts. Following incubation in defined media as required, cells were washed briefly in defined media, and then lysed by addition of $1 \mathrm{ml} 10 \mathrm{mM}$ Tris- $\mathrm{HCl}$ and $1 \%$ SDS ( $\mathrm{pH} 7 \cdot 5$ ), preheated to $95^{\circ} \mathrm{C}$. Extracts were transferred to $1.5 \mathrm{ml}$ tubes, and passed 5 times through a 25-gauge needle prior to heating for a further $5 \mathrm{~min}$. Aliquots $(50 \mu \mathrm{l})$ of extracts were stored at $-70{ }^{\circ} \mathrm{C}$ prior to electrophoresis.

Cellular proteins were resolved by polyacrylamide gel electrophoresis in a denaturing SDS buffer system (SDSPAGE), according to the method of Laemmli (1970). The acrylamide content of gels was $12 \%$, and they were run using the MiniProtean II system (BioRad, Hemel Hempstead, Herts, UK), at a constant current of $40 \mathrm{~mA} / \mathrm{gel}$.

Resolved proteins were transferred to polyvinylidene difluoride (PVDF) membranes (Polyscreen) by electroblotting, using the MiniTransblot wet transfer system (BioRad), according to the manufacturer's instructions. The buffer was $25 \mathrm{mM}$ Tris- $\mathrm{HCl}, 200 \mathrm{mM}$ glycine, $20 \% \mathrm{v} / \mathrm{v}$ methanol ( $\mathrm{pH} \quad 8 \cdot 5$ ), and transfers were conducted overnight at $40 \mathrm{~mA} /$ membrane and at room temperature.

Following transfer, membranes were washed briefly in $20 \mathrm{mM}$ Tris-HCl, $150 \mathrm{mM} \mathrm{NaCl}$ (pH 7.5) (TBS), containing $0 \cdot 1 \% \mathrm{v} / \mathrm{v}$ Tween 20 (TBST), and then incubated for $1 \mathrm{~h}$ at room temperature in TBST containing 3\% non-fat milk powder (Blotto). Membranes were incubated overnight in primary antibody solution containing anti-C/ EBP $\beta$ (Santa-Cruz Biotechnology, SC150, Santa Cruz, CA, USA) diluted 1:1000 in Blotto. The next day membranes were washed 5 times for $5 \mathrm{~min}, 50 \mathrm{ml} /$ wash in TBST, and then placed in secondary antibody solution containing anti-rabbit IgG-horseradish peroxidase conjugate (Transduction Laboratories, Lexington, KY, USA) diluted 1:2000 in Blotto. After the second antibody incubation, membranes were washed as before, and labelled proteins were visualised using the ECL chemiluminescence detection system (Amersham), according to the manufacturer's protocol in conjunction with Amersham Hyperfilm MP. Band quantitation was conducted using a LASER densitometer (Molecular Dynamics) and Phoretix I-D advanced image analysis software.

\section{Replication and statistical analyses}

For all the experiments described, specific treatments were performed in triplicate within a given experiment, and all experiments were performed on at least three separate hepatocyte cultures. Data from the studies of IGF-I production and protein synthesis rates were analysed by factorial ANOVA and comparison of individual sample means was made by Fisher's least significant difference test. C/EBP $\beta$ isoform labelling intensities were analysed by paired $t$-test. All analyses were conducted using Minitab version 11 (Minitab Inc., PA, USA). 
A

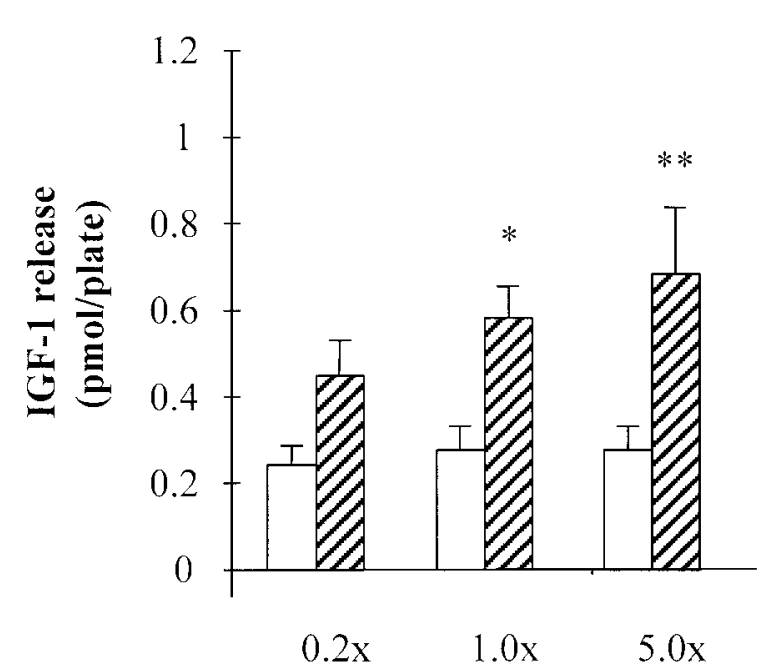

B

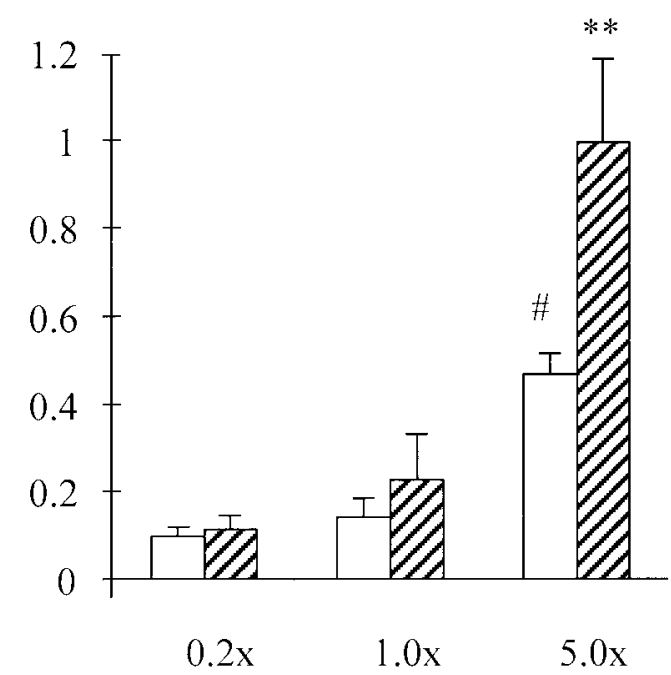

Figure 1 The effects of amino acid supply and GH on IGF-I release in cultured ovine hepatocytes. IGF-I release was measured after 24 (A) or $48 \mathrm{~h}$ (B) in defined media containing the indicated concentrations of amino acids. Data are plotted as absolute IGF-I release in the absence (open bars) or presence (hatched bars) of $\mathrm{GH}(10 \mathrm{nM})$ and are expressed as means \pm S.E.M. of values from three separate cultures. ${ }^{*} P<0 \cdot 05,{ }^{*} P<0 \cdot 01$, significantly greater production relative to values in the absence of $\mathrm{GH}$ in the same culture medium. $\# P<0 \cdot 05$, significantly increased basal production relative to values in $0 \cdot 2 \times$ or $1 \cdot 0 \times$ amino acid-containing media.

\section{Results}

The effects of amino acid supply on basal and GH-stimulated IGF-I peptide release by ovine hepatocytes

Over the first 24-h period in defined media, there was no significant effect of amino acid concentration on basal IGF-I release (Fig. 1A). Incubation with GH $(10 \mathrm{nM})$ caused a significant increase in IGF-I production in cells grown in $5.0 \times$ or $1.0 \times$ amino acid-containing media, with values being increased by at least $100 \%$ relative to basal values in both cases $(P<0.01$ and $P<0.05$ respectively). In contrast, $\mathrm{GH}$ did not have a statistically significant effect on IGF-I production by cells grown in $0 \cdot 2 \times$ amino acid media during this first incubation period, although a tendency towards increased release was observed.

In the period from 24 to $48 \mathrm{~h}$ in defined media, a highly significant effect of amino acid supply was also observed on basal IGF-I release, with values being more than 300\% higher in $5.0 \times$ amino acid media than in $0.2 \times$ amino acid media, and $200 \%$ greater than those in $1.0 \times$ amino acid media $(P<0.01$ and $P<0.05$ respectively; Fig. 1B). In addition, factorial ANOVA demonstrated a strong positive interaction between the responsiveness to $\mathrm{GH}$ and amino acid supply in the second 24-h period $(P<0 \cdot 001$; Fig. 1B), such that incubation with $\mathrm{GH}(10 \mathrm{nM})$ increased IGF-I release from cells in $5.0 \times$ amino acid media by more than twofold $(P<0 \cdot 01)$, but had no effect on IGF-I release by cells grown in either $1 \cdot 0 \times$ or $0 \cdot 2 \times$ amino acid media.

The effects of amino acid supply on IGF-I gene expression in ovine hepatocytes

The effects of amino acid supply and GH on levels of IGF-I and GAPDH RNA were assessed by RPA (Fig. 2). The IGF-I riboprobe recognised type 1 (exon 1-derived) IGF-I transcripts, giving a 405 base protected fragment, and also non-exon 1 transcripts giving a smaller fragment of 341 bases (Fig. 2A). A single protected fragment was observed with the GAPDH probe, levels of which were not affected by amino acid supply or GH (Fig. 2A). Consequently, changes in the expression of the different IGF-I fragments were normalised to GAPDH expression (Fig. 2B).

During the first 24-h period, GH stimulation induced a dramatic rise in the expression of both type 1 and nonexon 1 IGF-I transcripts in cells grown in 5.0 $\times$ amino acid media, but had no effect in $0 \cdot 2 \times$ amino acid media. Additionally basal levels of IGF-I expression appeared higher in $5.0 \times$ amino acid media than in $0.2 \times$ amino acid media in this first $24-\mathrm{h}$ period. A similar picture was also observed in the second $24-\mathrm{h}$ period, although there was a generalised decline in IGF-I expression relative to that observed in the preceding period. Overall, the effects of GH and amino acid supply appeared similar for both type 1 and non-exon 1 IGF-I transcripts. 


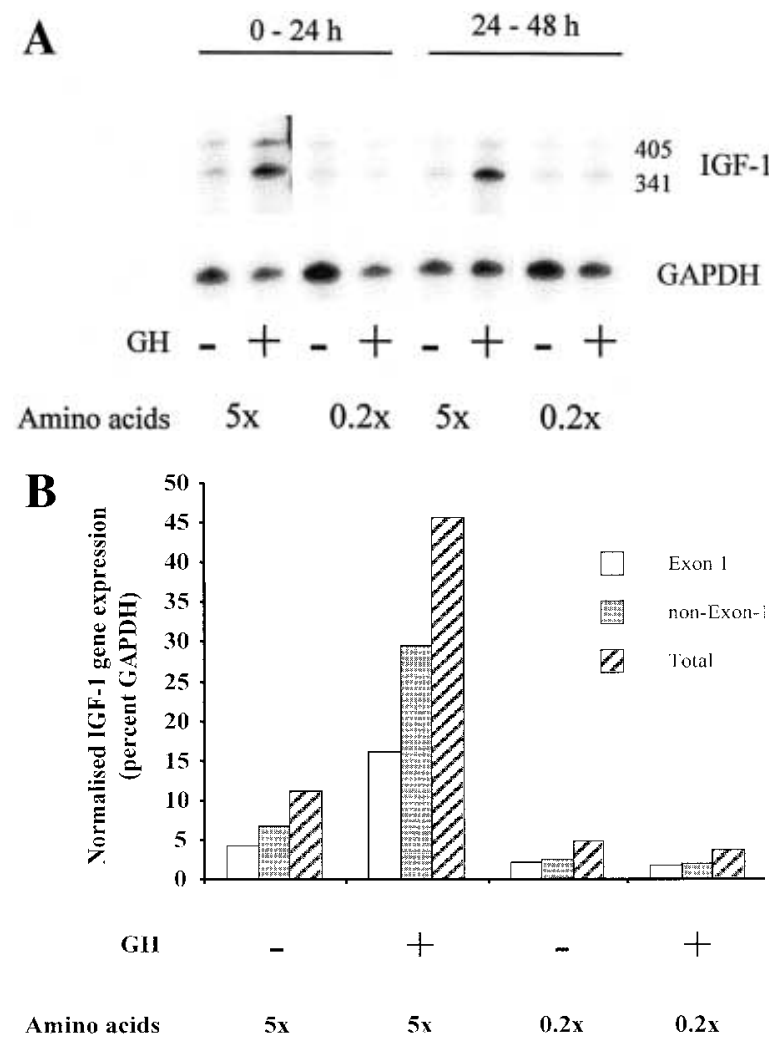

Figure 2 Effects of amino acid supply and GH on IGF-I RNA levels in cultured ovine hepatocytes. (A) Autoradiogram from a typical experiment showing the effects of amino acid supply $(5 \cdot 0 \times$ or $0 \cdot 2 \times$ physiological levels, see Materials and Methods) and GH $(10 \mathrm{nM})$, as indicated, on the intensity of protected fragments representing hybridisation of the IGF-I probe to exon 1 - and non-exon 1-derived IGF-I mRNA species (405 and 341 bases respectively). For comparison, the intensity of a second protected fragment, corresponding to hybridisation of a GAPDH probe to GAPDH mRNA in the same incubations is also shown.

(B) Histogram showing densitometric quantification of type-1 IGF-I mRNA levels in terms of integrated optical densities (IOD) of the 405 (open bars) and 341 (shaded bars) fragments expressed as percentages of the IOD of the corresponding GAPDH fragment. A combined value for both fragments is also shown (hatched bars).

\section{Cellular protein synthesis rates}

To evaluate the possible contribution of effects of amino acid availability on total cellular synthesis rates to the observed effects on IGF-I release, protein synthesis was quantified by ${ }^{35} \mathrm{~S}$-methionine labelling (Fig. 3). Protein synthesis over a 4-h incubation period, starting after $20 \mathrm{~h}$ culture in defined media, was linear at all levels of amino acid supply. Over three experiments, the incorporation in cells grown in $5.0 \times$ or $1.0 \times$ amino acid media was approximately 3 -fold higher than that observed in $0 \cdot 2 \times$ amino acid media $(P<0 \cdot 01)$. No effect of $\mathrm{GH}$ on methionine incorporation to cellular proteins was observed (data not shown).
Effect of amino acid supply on expression of protein isoforms of $C / E B P \beta$

Western immunoblotting of whole cell extracts from ovine hepatocytes with an antibody to C/EBP $\beta$ detected a major band with an apparent molecular mass of approximately $36 \mathrm{kDa}$, corresponding to the major translational product of the C/EBP $\beta$ gene, liver-enriched activating protein (LAP; Fig. 4A). In addition much weaker labelling of a $20 \mathrm{kDa}$ protein was observed, probably representing the truncated product of the $\mathrm{C} / \mathrm{EBP} \beta$ gene, liver-enriched inhibitory protein (LIP, Fig. 4A). Neither of these bands were observed when the primary antibody was omitted from the staining procedure (data not shown). Densitometric analysis showed that incubation in $0 \cdot 2 \times$ amino acid media for $24 \mathrm{~h}$ caused an approximately 2 -fold decrease in the expression of LAP relative to LIP, compared with that observed in $5.0 \times$ amino acid media $(P<0 \cdot 05$, Fig. 4B).

\section{Discussion}

The present study investigated the effects of $\mathrm{GH}$ and amino acid availability on IGF-I gene expression and peptide synthesis in primary ovine hepatocytes. The data presented demonstrate that these cells behave similarly to rat hepatocytes (Thissen et al. 1994) in that GH and amino acid supply interact synergistically to stimulate IGF-I gene expression. In addition this study is the first to demonstrate that this effect is also manifest at the level of IGF-I peptide release, further strengthening previous arguments based on in vivo data (MacRae et al. 1991) that amino acid-GH interactions at the level of the liver may be important physiologically.

Although the parallelism observed between the effects on RNA levels and those on peptide release suggests a causal link, a number of alternative possibilities also exist, involving translational efficiency or post-translational effects. With this in mind, the present study examined the effect of amino acid supply on protein synthetic rates in ovine hepatocytes. Amino acid limitation to $0 \cdot 2 \times$ physiological levels produced a $70 \%$ reduction in protein synthesis relative to that observed in $1.0 \times$ or $5.0 \times$ amino acid media. This effect is qualitatively similar to that observed previously in acutely isolated rat hepatocytes, in which synthesis rates in media containing $10 \times$ physiological concentrations of amino acids, or no amino acids were compared (Everson et al. 1989). Interestingly, the magnitude of the inhibition observed in that study was rather smaller $(\sim 30 \%)$, perhaps due to the much shorter acclimation period between initial isolation and initiation of metabolic labelling.

It is important to note that there was a clear lack of correspondence between the dose-dependent effects of amino acid supply on the synthesis of total cellular proteins, and those on basal or GH-stimulated IGF-I 


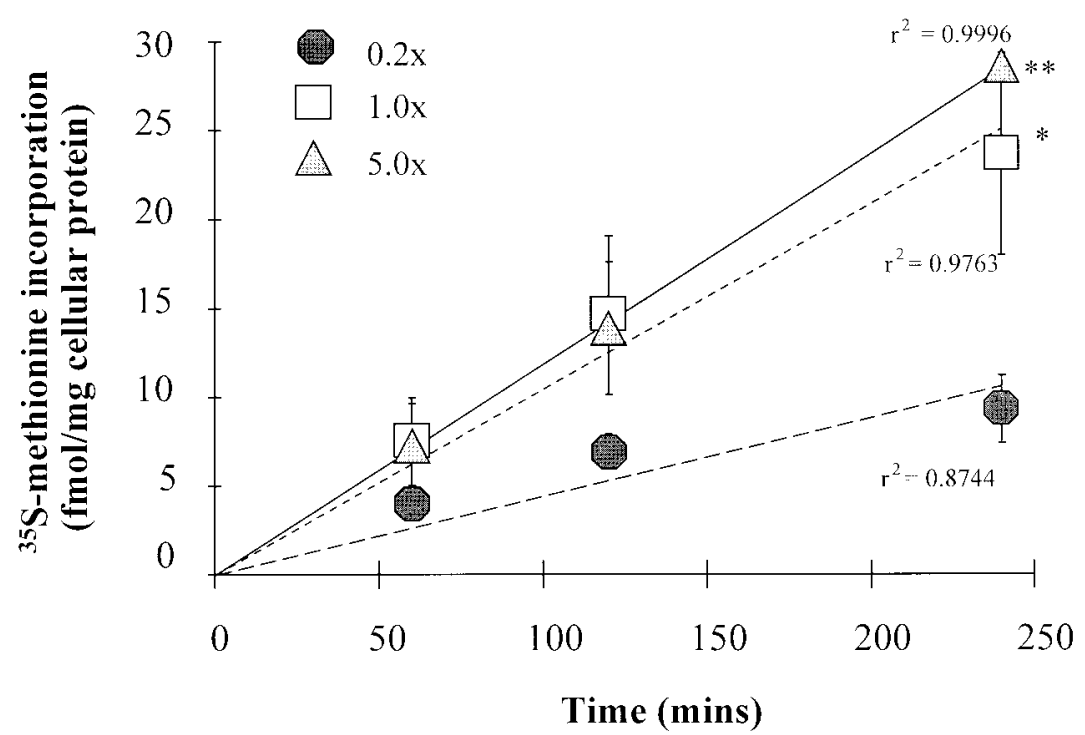

Figure 3 The effects of various amino acid concentrations on ${ }^{35} \mathrm{~S}$-methionine incorporation into total cellular TCA-precipitated protein. Triplicate plates were incubated in $0.2 \times, 1.0 \times$ or $5.0 \times$ physiological concentrations of amino acids, as indicated. After culture as described, methionine incorporation was measured over a 4-h period. Results are means \pm S.E.M. of three separate cultures. ${ }^{*} P<0 \cdot 05,{ }^{* *} P<0 \cdot 01$, significantly greater incorporation relative to values in $0 \cdot 2 \times$ amino acid media at the same time point.

A

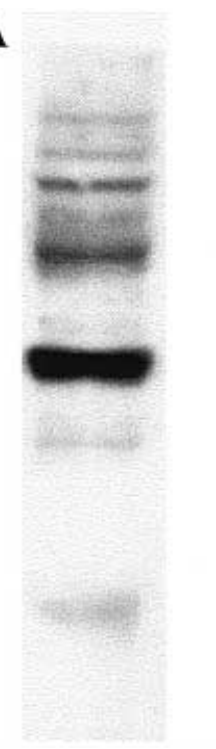

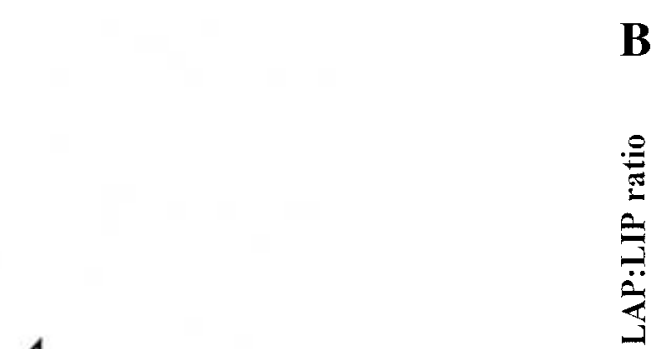

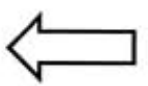

$36 \mathrm{kDa}$

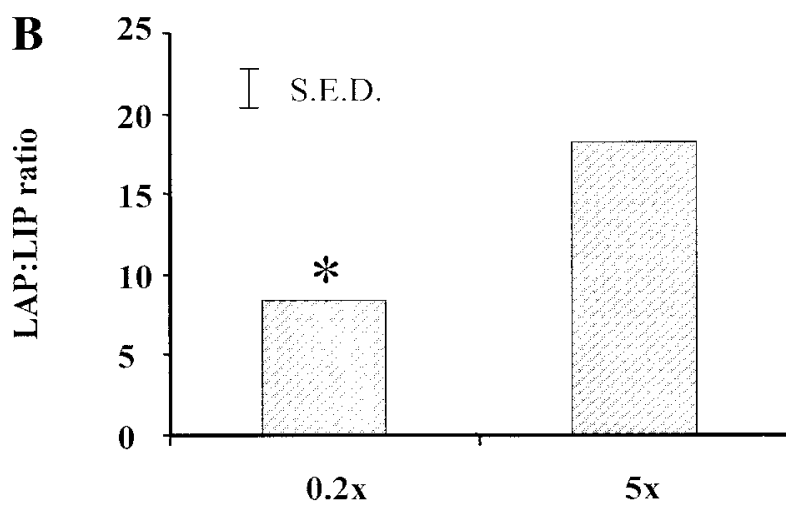

Amino acid level

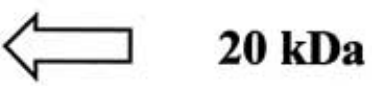

Figure 4 Effect of amino acid supply on C/EBP $\beta$ protein isoform expression in ovine hepatocytes. (A) Typical image obtained after ECL detection of immunostained proteins extracted as described in Materials and Methods; bands corresponding to LAP (36 kDa) and LIP $(20 \mathrm{kDa})$ are indicated. (B) Histogram showing levels of LAP (integrated optical densities obtained from LASER densitometry) expressed as a ratio to LIP expression in the same samples. Data are means of values from 3 separate experiments; the standard error of the difference (S.E.D.) is shown for comparison. ${ }^{*} P<0 \cdot 05$, significantly reduced LAP:LIP ratio compared with that in $5 \cdot 0 \times$ amino acid media.

production. Throughout the experiment, basal IGF-I production was similar in both $0 \cdot 2 \times$ and $1 \cdot 0 \times$ amino acid media, although synthesis of cellular proteins differed dramatically under the same conditions. Conversely in the period 24-48 h, IGF-I production in $1 \cdot 0 \times$ amino acid media was reduced by $70-80 \%$ relative to that seen in $5 \cdot 0 \times$ amino acid media, although protein synthesis rates were unaffected.

The distinction between the effects of amino acid supply on total cellular synthesis rates and those on IGF-I 
production suggests that selective regulatory mechanisms are operative. Potentially such effects could come through regulation of IGF-I gene expression, a view which is supported by correlative evidence from in vivo studies in sheep (Pell et al. 1993), and could arise through alterations in transcription, post-transcriptional processing or RNA stability.

Previous in vivo studies have shown that protein restriction leads to changes in the levels of several members of the C/EBP family (Marten et al. 1996); however the mechanisms through which these responses to diet occurred were not investigated. Since it is known that the IGF-I promoter contains a CCAAT/enhancer consensus sequence (Nolten et al. 1994), the present study explored the possibility that the effects of amino acids on IGF-I gene expression were associated with a change in the relative levels of stimulatory/inhibitory isoforms of C/EBP. Based on the studies of Marten and co-workers (1996), in which C/EBP $\beta$ isoforms were shown to be sensitive to the level of protein in the diet, the present study focused on the two alternative translation products of the C/EBP $\beta$ RNA, LAP and LIP. Consistent with that previous study a significant increase in the relative expression of LIP was observed under amino acid limiting conditions.

The biological significance of this finding, especially its relationship to the other effects reported here, remains to be established. Both under the conditions tested here and in all previous studies, LIP has been found to be expressed at much lower levels than LAP; nevertheless LIP has a significantly higher affinity for CCAAT/enhancer consensus sequences than LAP, and thus probably acts as a dominant repressor of CCAAT/enhancer regulated gene expression (Descombes \& Schibler 1991). Hence the comparatively weak levels of LIP immunoreactivity observed in the present study could conceivably exert a significant repressive effect on IGF-I gene expression.

An intriguing aspect of the control of LAP/LIP isoform expression is that it depends directly upon alternative start site usage in C/EBP $\beta$ mRNAs. Thus the change in the relative levels of LAP and LIP is most likely attributable to amino acid-dependent modulation of ribosomal function - leading to a selective change in translational efficiency. This interpretation has attractive parallels with earlier work demonstrating that amino acids control gene expression in yeast by altering the efficiency of translation of mRNA for the transcription factor GCN4 (Dever et al. 1992). The relationship between the effects on amino acids on eukaryotic initiation factor activity in hepatocytes, and the link between initiation factor activity and hepatocyte gene expression will be instructive areas for future research.

The effects of amino acid supply on C/EBP $\beta$ protein isoforms notwithstanding, it remains possible that the effects of amino acids on IGF-I mRNA levels depend on RNA stability rather than transcription rates. This possibility has been argued for by Underwood and coworkers (Zhang et al, 1997), and is supported by recent studies of the decay of IGF-I RNA levels in rat hepatocytes under transcriptional blockade (Zhang et al. 1998). Clearly there is a need for further studies to dissect the relative importance of transcription and RNA stability to the phenomena described here.

Finally, the possibility that amino acid supply affects the efficiency of translation of IGF-I mRNAs more dramatically than it affects overall translation rates cannot be excluded by the present study. Indirect evidence to support such a model comes from studies of the in vitro translatability of different IGF-I transcripts (Yang et al. 1995), and from studies of their polysomal association (Foyt et al. 1991). Nevertheless, the findings that GH does not appear to affect the polysomal association of different IGF-I mRNA species (Foyt et al. 1992), and that GH has no effect on overall protein synthesis rates in hepatocytes (data not shown), make it difficult to explain synergistic effects in terms of translational efficiency alone.

In summary, the current study demonstrates that amino acid supply and GH interact to control IGF-I gene expression and IGF-I release in ovine hepatocytes. That this is part of a selective response to altered nutrient availability is supported by the dissociation between this effect and that on total cellular protein synthesis, and by the selective increase in LIP relative to LAP. The causal links between these effects and their significance in medical and agricultural contexts will be the subject of future investigations.

\section{Acknowledgements}

The authors thank the following organisations for support: BBSRC (N M W, M A L); SHEFC (D G H, M A L) and SOAEFD (J C M).

\section{References}

Barrett P, MacLean A, Davidson G \& Morgan PJ 1996 Regulation of the Mel 1a melatonin receptor mRNA and protein levels in the ovine pars tuberalis: evidence for a cyclic adenosine $3^{\prime}, 5^{\prime}$-monophosphateindependent Mel 1a receptor coupling and an autoregulatory mechanism of expression. Molecular Endocrinology 10 892-902.

Bates PC, Loughna PT, Pell LM, Schulster D \& Millward DJ 1993 Interactions between growth hormone and nutrition in hypophysectomized rats: body composition and production of insulin-like growth factor-I. Journal of Endocrinology 139 117-126.

Breier BH, Gluckman PD \& Bass JJ 1988 Influence of nutritional status and oestradiol-17 $\beta$ on plasma growth hormone, insulin-like growth factors-I and -II and the response to exogenous growth hormone in young steers. Journal of Endocrinology 118 243-250.

Breier BH, Gallaher BW \& Gluckman PD 1991 Radioimmunoassay for insulin-like growth factor-I: solutions to some potential problems and pitfalls. Journal of Endocrinology 128 347-357.

Chomczynski P \& Sacchi N 1987 Single-step method of RNA isolation by acid guanidinium isothiocyanate-phenol-chloroform extraction. Analytical Biochemistry 162 156-159. 
Counts DR, Gwirtsman H, Carlsson LM, Lesem M \& Cutler GB Jr 1992 The effect of anorexia nervosa and refeeding on growth hormone-binding, the insulin-like growth factors (IGFs), and the IGF-binding proteins. Journal of Clinical Endocrinology and Metabolism $75762-767$.

Daughaday WH \& Rotwein P 1989 Insulin-like growth factors I and II. Peptide messenger ribonucleic acid and gene structures, serum, and tissue concentrations. Endocrine Reviews 10 68-91.

Descombes P \& Schibler U 1991 A liver-enriched transcriptional activator protein, LAP, and a liver-enriched transcriptional inhibitory protein, LIP, are transcribed from the same mRNA. Cell 67 569-579.

Dever TE, Feng L, Wek RC \& Cigan AM 1992 Phosphorylation of initiation factor 2 alpha by protein kinase GCN2 mediates gene-specific translational control of GCN4 in yeast. Cell $\mathbf{6 8}$ 585-596.

Elsasser TH, Rumsey TS \& Hammond AC 1989 Influence of diet on basal and growth hormone-stimulated plasma concentrations of IGF-I in beef cattle. Journal of Animal Science 67 128-141.

Everson WV, Flaim KE, Susco DM, Kimball SR \& Jefferson LS 1989 Effect of amino acid deprivation on initiation of protein synthesis in rat hepatocytes. American Journal of Physiology 256 C18-C27.

Foyt HL, LeRoith D \& Roberts CT Jr 1991 Differential association of insulin-like growth factor I mRNA variants with polysomes in vivo. Journal of Biological Chemistry 266 7300-7305.

Foyt HL, Lanau F, Woloschak M, LeRoith D \& Roberts CT Jr 1992 Effect of growth hormone on levels of differentially processed insulin-like growth factor I mRNAs in total and polysomal mRNA populations. Molecular Endocrinology 6 1881-1888.

Gluckman PD, Breier BH \& Davis SR 1987 Physiology of the somatotropic axis with particular reference to the ruminant. Journal of Dairy Science 70 442-466.

Harp JB, Goldstein S \& Phillips LS 1991 Nutrition and somatomedin XXIII. Molecular regulation of IGF-I by amino acid availability in cultured hepatocytes. Diabetes 40 95-101.

Kimball SR, Antonetti DA, Brawley RM \& Jefferson LS 1991 Mechanism of inhibition of peptide chain initiation by amino acid deprivation in perfused liver. Journal of Biological Chemistry 266 1969-1976.

Krebs HA, Cornell NW, Lund P \& Hems R 1974 Isolated liver cells as experimental material. In Regulation of Hepatic Metabolism, Alfred Benzon Symposium 6, pp 726-750. Eds F Lundquist \& H Tygstrup. Copenhagen: Munksgaard.

Kriel GV, Bryant MJ \& Lomax MA 1992 Effect of dietary protein intake and intravenous glucose infusion on plasma concentrations of insulin-like growth factor-I in lambs. Journal of Endocrinology 132 195-199.

Laemmli UK 1970 Cleavage of structural proteins during the assembly of the head of the bacteriophage T4. Nature 227 680-685.

Lobley GE, Connell A, Lomax MA, Brown DS, Milne E, Calder AG \& Farningham DAH 1995 Hepatic detoxification of ammonia in the ovine liver: possible consequences for amino acid catabolism. British Journal of Nutrition 73 667-685.

Luo QJ, Maltby SA, Lobley GE, Calder AG \& Lomax MA 1995 The effect of amino acids on the metabolic fate of ${ }^{15} \mathrm{NH}_{4} \mathrm{Cl}$ in isolated sheep hepatocytes. European Journal of Biochemistry 228 912-917.

MacRae JC, Bruce LA, Hovell FD DeB, Hart IC, Inkster J, Walker A \& Atkinson T 1991 Influence of protein nutrition on the response of growing lambs to exogenous bovine growth hormone. Journal of Endocrinology 130 53-61.

Marten NW, Burke EJ, Hayden JM \& Strauss DS 1994 Effect of amino acid limitation on the expression of 19 genes in rat hepatoma cells. FASEB Journal 8 538-544.

Marten NW, Sladek FM \& Strauss DS 1996 Effect of dietary protein restriction on liver transcription factors. Biochemical Journal $\mathbf{3 1 7}$ 361-370.

Nolten LA, van Schiak FMA, Steenbergh P \& Sussenbach JS 1994 Expression of the insulin-like growth factor-I gene is stimulated by the liver-enriched transcription factors $\mathrm{C} / \mathrm{EBPa}$ and LAP. Molecular Endocrinology 8 1636-1645.

Pell JM, Saunders JC \& Gilmour RS 1993 Differential regulation of transcription initiation from insulin-like growth factor-I (IGF-I) leader exons and of tissue IGF-I expression in response to changed growth hormone and nutritional status in sheep. Endocrinology 132 1797-1807.

Schwander JC, Hauri C, Zapf J \& Froesch ER 1983 Synthesis and secretion of insulin-like growth factor and its binding protein by the perfused rat liver: dependence on growth hormone status. Endocrinology 113 297-305.

Sohlstrom A, Katsman A, Kind KL, Grant PA, Owens PC, Robinson JS \& Owens JA 1998 Effects of acute and chronic food restriction on the insulin-like growth factor axis in the guinea-pig. Journal of Endocrinology 157 107-114.

Thissen J-P, Pucilowski JB \& Underwood LE 1994 Differential regulation of insulin-like growth factor I (IGF-I) and IGF binding protein-1 messenger ribonucleic acids by amino acid availability and growth hormone in rat hepatocyte primary culture. Endocrinology 134 1570-1576.

VandeHaar MJ, Moats-Staats BM, Davenport ML, Walker JL, Ketelslegers J-M, Sharma BK \& Underwood LE 1991 Reduced serum concentrations of insulin-like growth factor-I (IGF-I) in protein-restricted growing rats are accompanied by reduced IGF-I mRNA levels in liver and skeletal muscle. Journal of Endocrinology 130 305-312.

Wyn PC, Stuart MC, Wallace ALC, Kirby AC \& Annison EF 1991 Influence of nutritional status on growth hormone-dependent circulating somatomedin-C in mature sheep. Journal of Endocrinology 130 313-320.

Yang H, Adamo ML, Kovat AP, McGuinness C, Ben-Hur H, Yang Y, LeRoith D \& Roberts CT Jr 1995 Alternative leader sequences in insulin-like growth factor I mRNAs modulate translational efficiency and encode multiple signal peptides. Molecular Endocrinology 9 1380-1395.

Zhang J, Whitehead Jr RE \& Underwood LE 1997 Effect of fasting on insulin-like growth factor (IGF)-IA and IGF-IB messenger ribonucleic acids and prehormones in rat liver. Endocrinology 138 3112-3118.

Zhang JH, Chrysis D \& Underwood LE 1998 Reduction of hepatic insulin-like growth factor I (IGF-I) messenger ribonucleic acid (mRNA) during fasting is associated with diminished splicing of IGF-I pre-mRNA and decreased stability of cytoplasmic IGF-I mRNA. Endocrinology 139 4523-4530.

Received 8 February 1999

Revised manuscript received 1 June 1999 Accepted 30 June 1999 